\title{
Cutaneous Squamous Cell Carcinoma in Faghihi Hospital Patients (Shiraz, Iran) in 2015 - 2016: Epidemiological Study
}

\author{
Sina Zamani ${ }^{1}$, Sara Zamani ${ }^{2}$ and Mohammad Reza Namazi (iid ${ }^{3,{ }^{*}}$ \\ ${ }^{1}$ School of Medicine, Shiraz University of Medical Sciences, Shiraz, Iran \\ ${ }^{2}$ Department of Microbiology and Microbial Biotechnology, Faculty of Life Sciences and Biotechnology, Shahid Beheshti University, Tehran, Iran \\ ${ }^{3}$ Dermatology Department, School of Medicine, Shiraz University of Medical Sciences, Shiraz, Iran \\ "Corresponding author: MD, Associate Professor, Dermatology Department, School of Medicine, Shiraz University of Medical Sciences, Shiraz, Iran. Email: \\ namazim2019@gmail.com
}

Received 2019 July 21; Revised 2019 September 15; Accepted 2019 September 21.

\begin{abstract}
Background: Cutaneous Squamous Cell Carcinoma (cSCC) is an invasive primary cutaneous malignancy and the second common cancer among whites.

Objectives: To define the frequency and epidemiologic features of CSCC.

Methods: This study was carried out on 311 patients referred to the Department of Dermatology at Faghihi Hospital of Shiraz, Southwest Iran, between 2015 - 2016. cSCC was diagnosed by pathologists using the standard criteria. The reports were collected along with general information such as age, sex, location, type, and depth of invasion; then it was analyzed by using the statistical software known as SPSS version 23.0 and Minitab software version 18. Chi-square test was used to evaluate the statistical significance. A $P$ value lower than 0.05 was considered as significant.

Results: The age range of patients was 21 - 95 years old with an average age of 67.63 . The sex ratio (male to female) was 2.87 for the total number of cases. The most common stage was well differentiation $97(31.2 \%)$. The most frequent tumor thickness was between two to four millimeters and the most frequent lesion locations were the nose and then the scalp.

Conclusions: The frequency of CSCC increased over the years in regards to patients that were referred to the Faghihi Hospital. This results along with other data which are available from other hospitals and medical centers confirm that the frequency of cSCC is increasing in Iran and plan for management of CSCC is essential, nationally.
\end{abstract}

Keywords: Epidemiology, Cutaneous Squamous Cell Carcinoma, Shiraz

\section{Background}

Cutaneous Squamous Cell Carcinoma (cSCC) is an invasive primary cutaneous malignancy arisen from keratinocytes of the skin and mucosal surface. Tumor cells are classified based on the cancer cell differentiated into well (WDC), moderately (MDC), and poorly differentiated carcinoma (PDC). Differentiation is used in the tumor grading system (1-3). It is considered as the second common cancer among whites $(4,5)$. cSCC is about $20 \%$ of nonmelanoma skin cancers (6). Australia and the United States have the highest cSCC rate of occurrence (7). About 100000 new cases of primary squamous cell carcinoma are diagnosed in the United States each year and about 2500 deaths occur annually. Although the incidence rate of other skin malignancies has not been increased, squamous cell carcinoma and basal cell carcinoma are still increasing $(1,2,8,9)$.

The most important cause of squamous cell carcinoma is DNA damage induced by ultraviolet light caused by the depletion of the ozone layers $(5,10,11)$. Ultraviolet B radiation with ultraviolet A from sunlight are mainly responsible for cSCC. Fair-skinned people and blonde or red hair are up to five times higher than those with darker features for the development of skin cancer (5).

Chemical carcinogens like arsenic and chromium, human papilloma virus infections, ionizing radiation exposure, immunodeficiency, chronic inflammation like near chronic ulcers, genetic conditions, pre-malignant conditions like areas of skin showing actinic damage, industrial carcinogens like oil and tars, smoking, and family history of squamous cell carcinoma are other risk factors (1-5, 8, 9, $12,13)$.

On the other hand, studies show that cSCCs, with some tumor factors like tumor recurrence, diameter greater than or equal to $2 \mathrm{~cm}$, location on the ear, vermilion lip, mask areas of the face, hands, feet, genitalia or in embryonic fusion planes, thickness greater than $2 \mathrm{~mm}$, poorly differentiated history, or invasion of the subcutaneous tissue 
or structures such as perineural, vascular, or lymphatic tissue have a greater risk of metastasis (14).

\section{Objectives}

Therefore, monitoring of cSCC frequency and epidemiologic features are necessary for assessment of health-care requirements. The aim of this study is to define the frequency and epidemiology of cSCC at the Faghihi Hospital, in Shiraz, Iran in 2015 and 2016.

\section{Methods}

This descriptive cross-sectional study was carried out on 311 patients who referred to the Department of Dermatology at Faghihi Hospital of Shiraz, Southwest Iran, in 2015 and 2016. These patients had plaque like lesions, verrucous or nodular tumors, or lesions with ulceration that were referred to the Faghihi Hospital and were chosen for biopsy. Cutaneous Squamous Cell Carcinoma was diagnosed by pathologists using standard criteria. The reports were collected along with general information such as age, sex, location, type, and depth of invasion.

In this study, we separated the site of the lesions such as the eyelid, chin, cheek, forehead, and other sites of the face just defined as face. Then, after collecting the patients' phone numbers, we collected the information such as the history of using any immunosuppressant drugs, and burn scars on the site of a tumor.

After gathering lab data that collected from the pathology laboratory and checking the pathology reports, the data were described and then analyzed by using a statistical software known as SPSS version 23.0 (Released 2013. Armonk, NY: IBM Corp.) and Minitab software version 18. The chi-square test was used to evaluate the statistical significance. A P value of $<0.05$ was considered significant.

\section{Results}

During the study period (2015 - 2016), 502 incidents of squamous cell carcinoma were diagnosed at the Faghihi Hospital of Shiraz, Iran. Among 502 tumors, 311 cases were Cutaneous Squamous Cell Carcinoma and the others were non-skin squamous cell carcinoma like esophageal squamous cell carcinoma or lung squamous cell carcinoma. To define exactly the results in 2015 and 2016, we can see a total of 144 and 167 cases with cSCC, respectively. Data distribution showed that in 2015: the age range of patients was 28 - 93 years old with an average age of 67.31 years and standard deviation was 16.25, in 2016: the age range of patients was 21 - 95 years old with an average age of 67.92 years and standard deviation was 16.56. In total (2015 - 2016), the age range of patients was 21 - 95 years old with an average age of 67.63 and standard deviation was 16.39 .

Cutaneous Squamous Cell Carcinoma was most common in men: 238 cases (73.3\%), while the frequency in women was 83 cases (36.7\%). The sex ratio (male to female) was 2.87 for the total number of cases. The most frequent lesion locations were nose: 58 cases (18.6\%) and scalp: 57 cases (18.3\%). Ulcerative lesions frequency was 45 cases (14.5\%). Among all, 13 cases were registered as a possible case of skin cancer and seven cases (2.3\%) of the patients had metastasis before starting this study. The most common stage of cSCC was well differentiation: 97cases (31.2\%). The most frequent tumor thickness was between two to four millimeters with the most frequent of three millimeters in depth of lesion. In this study, the frequency of people who used immunosuppressant drugs such as prednisolone, hydrocortisone, tacrolimus, cyclosporine, azathioprine, etanercept, or had a history of drugs for their organ transplantation, if they had a history of organ transplantation, was 273 cases. It shows that 38 cases (12.2\%) used these drugs. In addition, 14 (4.5\%) of them had a history of burn scar before their biopsy on the site of their lesion. It shows that 14 cases (4.5\%) of them had lymphovascular invasion.

Frequency of cSCC by sex, pathological history, anatomical location, and other factors were shown in Table 1.

In order to evaluate the statistical significance of variables between 2015 and 2016, chi-square test was used. The distribution between cases in 2015 and 2016 were not significantly different for age $(\mathrm{P}=0.744)$. There was no significant difference $(\mathrm{P}=0.713)$ for sex between patients in 2015 and 2016. In addition, distribution of the anatomical location in 2015 and 2016 was not significant $(P=0.601)$. However, there was a significant difference $(P<0.001)$ in frequency of cases with the lesions with ulceration between 2015 and 2016. Frequency of this variable was 5.6\% in 2015 and was increased to $22.2 \%$ in 2016 . There was no significant difference $(P=0.561)$ between 2015 and 2016 in the frequency of metastasis. In this study, a significant difference $(\mathrm{P}<0.001)$ in different pathological history was diagnosed; for instance, the frequency of MT group was $0.7 \%$ in 2015 and it increased to $20.1 \%$ in 2016 , or the frequency of MDC group in 2015 was $25.7 \%$ and decreased to $20.6 \%$ in 2016. Distribution of the tumor thickness in patients was significantly different $(\mathrm{P}=0.001)$ in 2015 and 2016; for example, the group with a tumor thickness that equals to $1 \mathrm{~mm}$ in 2015 was $4.2 \%$ and decreased to $0.6 \%$ in 2016 , or the group with a tumor thickness of $4 \mathrm{~mm}$ in 2015 was $9 \%$ and increased to $21 \%$ in 2016 . There was no significant difference $(P=0.389)$ for frequency of immunosuppressant drugs acquisition between patients in 2015 and 2016. The frequency of burn scar in the patients did not have a significant difference $(P=0.403)$ in 2015 and 2016. Frequency of 
cases with lymphovascular invasion had a significant difference $(P=0.014)$ in 2015 and 2016; it increased from 1.4\% in 2015 to $7.2 \%$ in 2016 .

\section{Discussion}

Skin cancer is now one of the prevalent types of cancer in the world and also in Iran. However, mortality from this cancer is low $(15,16)$. Due to the increase in population, life anticipation, the elderly population ratio, socio-economic status, and life style changes make Iran as the country at a high risk of skin cancer. Razi et al., showed that the trend of skin cancer incidence is increasing in Iran. In addition, the sex ratio was more in men than women in Iran. Their investigation demonstrates that the highest rate of skin cancer was at 80 - 84 years (17). In their study, the highest incidence of skin cancer in women was observed in the Semnan province, Yazd province, and Fars province (Shiraz is located in Fars province), respectively. On the other hand, they demonstrated the highest incidence of skin cancer in men were in the Semnan province, Fars province, Hamedan province, and Tehran province (15).

Cutaneous squamous cell carcinoma, cSCC (nonmelanoma type of skin cancer) is the most frequent form of skin cancer in most of countries in the world (18). Razi et al., showed that CSCC, has a maximum rising in annual incidences average $8 \%$ in Iran (17). Many causes and risk factors can be mentioned for that such as an exposure to ultra violet light from the sun and artificial sources, ozone depletion, indoor tanning, and also genetic defects that make a decrease in DNA repair. Due to the increase of longevity general population, we can mention that an increase incidence of non-melanoma skin cancer is related to increasing age (15-17).

Gurudutt and Genden (19), and Kabir et al. (20), findings showed that large tumors, deep tissue invasion, location in high risk areas, and immunosuppression are implicated in worsening prognosis. According to these investigations, this study tries to notice the risk factors. Our finding in patients referred to Faghihi Hospital in Shiraz confirms the Kabir et al., study in the Iranian population. Kabir et al., reported that skin cancer increased between 2003 and 2008 in the Iranian population (20). Similar to the findings of Kabir et al., in our study the frequency of cSCC in males is more than in females. Their study showed that the standardized incidence rate(SIR) of skin cancer increased from 10.05 and 13.89 in 2003 to 15.57 and 22.62 in 2008 in women and men, respectively (20). The rate did not increase significantly based on anatomical locations in 2015 and 2016 and the highest frequency of anatomical location of the tumor was nose and scalp. The face and head are often without covering or protection and these anatomical locations are more exposed to UV radiation.
Therefore, our findings support the effect of UV exposure in cSCC. Robsahm et al., showed a significant increase in all anatomical locations (except ears in female) from 1963 - 2011, and most cSCC occurred in the head and face area (7). Similar to our findings Kabir et al., declared that most tumor locations were associated with poor outcomes including the ear, cheek, lip, temple, and anogenital area (20). In our study, there was no significantly increase in age frequency in 2015 to 2016, maximum age for cSCC was 95 and it was higher than the Robsahm et al., investigation, which had an age group 70 - 79 years (7). Another factor that may have contribution to higher cSCC rate is the increasing number of long-term use of immune-suppressive drugs. The radio rate of immunosuppressant drugs acquisition in patients was about 0.14 in our study; the Kabir et al., study confirms our study. They declared that cSCC is the most common cancer in organ transplant recipients. They said that the increased incidence of cSCC is tied to immunosuppressive medicines, including calcineurin inhibitors (cyclosporine and tacrolimus) azathioprine, mycophenolic acid (mycophenolate mofetil and mycophenolate sodium), and prednisone (20).

In the current study, the most frequent tumor thickness was $3 \mathrm{~mm}$ and the most frequent pathological history was well differentiated squamous cell carcinoma. On the other hand, studies examining millimeter depth have shown that the threshold for poor outcomes is anywhere between $2 \mathrm{~mm}$ and $6 \mathrm{~mm}$ and also poorly differentiated tumors have increased risk of poor outcomes (20). In this study, the frequency of lymphovascular invasion and the lesions with ulceration increased significantly. The frequency of metastases and burn scar were not significantly different in 2015 and 2016.

This study confirms that the frequency of new cases of cSCC in patients referred to Faghihi Hospital in Shiraz increased, which is in agreement with the entire world. The results of the study can help the physicians know more about the frequency and epidemiologic features of squamous cell carcinoma of the skin among the population of Shiraz, southwest Iran.

Limitations of this study are: (1) gathering of data and pathology reports: some data were excluded because of not being complete or did not have the exact information such as the anatomical location of the skin tumor. (2) Gathering the information of history of using immunosuppressant drugs or history of burn scars: we just had some of the patient information to ask them and some patients did not cooperate. (3) In this study, we have just the information of Faghihi Hospital of Shiraz and we do not have the other laboratories and hospital information and one of the most important reason for that is the other hospitals do not have a systematized information to access to them easily. (4) Missed skin cancers that had been diagnosed clinically or 
even treated without a biopsy.

Due to the fact that this study is the first one in our region, physicians can use this database for prevention, screening, and treatment of patients in a more efficient way, and can also give future studies a better prospect of future skin cancers prognosis.

\subsection{Conclusions}

Nowadays, people are more aware of diseases and harmful effects of ultra violet radiation, so, they use sunscreen more than before. Regarding to facilities in the health care systems in, our region, Shiraz, Southwest Iran, patients refer to the physician earlier. Since the most common site of the tumor is in their face or skin, so they may be noticed easy and at the early stage and physicians will diagnose the tumor more easily.

\section{Footnotes}

Authors' Contribution: All authors have the same contribution.

Conflict of Interests: The authors declare that there was no conflict of interest.

Ethical Approval: All procedures performed in studies on individuals were in accordance with the ethical standards of the Institutional and/or National Research Committee and with the 1964 Helsinki Declaration and its later amendments or comparable ethical standards.

Funding/Support: This study was financially supported by the School of Medicine, Shiraz University of Medical Sciences, Shiraz, Iran.

Patient Consent: Informed consent was obtained from all individual participants included in the study.

\section{References}

1. Kanitakis J, Petruzzo P, Gazarian A, Testelin S, Devauchelle B, Badet $\mathrm{L}$, et al. Premalignant and malignant skin lesions in two recipients of vascularized composite tissue allografts (face, hands). Case Rep Transplant. 2015;2015:356459. doi: 10.1155/2015/356459. [PubMed: 26550517]. [PubMed Central: PMC4621363].

2. Yanofsky VR, Mercer SE, Phelps RG. Histopathological variants of cutaneous squamous cell carcinoma: A review. J Skin Cancer. 2011;2011:210813. doi: 10.1155/2011/210813. [PubMed: 21234325]. [PubMed Central: PMC3018652].

3. Padma R, Kalaivani A, Sundaresan S, Sathish P. The relationship between histological differentiation and disease recurrence of primary oral squamous cell carcinoma. J Oral Maxillofac Pathol. 2017;21(3):461. doi: 10.4103/jomfp.JOMFP_241_16. [PubMed: 29391735]. [PubMed Central: PMC5763883].

4. Alam M, Ratner D. Cutaneous squamous-cell carcinoma. N Engl J Med. 2001;344(13):975-83. doi: 10.1056/NEJM200103293441306. [PubMed: $11274625]$.
5. Que SKT, Zwald FO, Schmults CD. Cutaneous squamous cell carcinoma: Incidence, risk factors, diagnosis, and staging. J Am Acad Dermatol. 2018;78(2):237-47. doi: 10.1016/j.jaad.2017.08.059. [PubMed: 29332704].

6. Karia PS, Han J, Schmults CD. Cutaneous squamous cell carcinoma: Estimated incidence of disease, nodal metastasis, and deaths from disease in the United States, 2012. J Am Acad Dermatol. 2013;68(6):957-66. doi:10.1016/j.jaad.2012.11.037. [PubMed: 23375456].

7. Robsahm TE, Helsing P, Veierod MB. Cutaneous squamous cell carcinoma in Norway 1963-2011: Increasing incidence and stable mortality. Cancer Med. 2015;4(3):472-80. doi: 10.1002/cam4.404. [PubMed: 25620456]. [PubMed Central: PMC4380972].

8. Schmults CD, Karia PS, Carter JB, Han J, Qureshi AA. Factors predictive of recurrence and death from cutaneous squamous cell carcinoma: A 10-year, single-institution cohort study. JAMA Dermatol. 2013;149(5):541-7. doi: 10.1001/jamadermatol.2013.2139. [PubMed: 23677079].

9. Estall V, Allen A, Webb A, Bressel M, McCormack C, Spillane J. Outcomes following management of squamous cell carcinoma of the scalp: A retrospective series of 235 patients treated at the Peter MacCallum Cancer Centre. Australas J Dermatol. 2017;58(4):e207-15. doi: 10.1111/ajd.12520. [PubMed: 27283245].

10. Martin Garcia E, Arias-Santiago S, Serrano-Ortega S, BuendiaEisman A. Changes in the incidence of skin and lip cancer between 1978 and 2007. Actas Dermosifiliogr. 2017;108(4):335-45. doi: 10.1016/j.ad.2016.11.016. [PubMed: 28190452].

11. Adabi S, Hosseinzadeh M, Noei S, Conforto S, Daveluy S, Clayton A, et al. Universal in vivo textural model for human skin based on optical coherence tomograms. Sci Rep. 2017;7(1):17912. doi:10.1038/s41598-017 17398-8. [PubMed: 29263332]. [PubMed Central: PMC5738372].

12. Zamani S, Sohrabi A, Rahnamaye-Farzami M, Hosseini SM. Glutathione S-transferase omega gene polymorphism as a biomarker for human papilloma virus and cervical cancer in Iranian women. J Turk Ger Gynecol Assoc. 2018;19(4):193-200. doi: 10.4274/jtgga.2018.0056. [PubMed: 30115608]. [PubMed Central: PMC6250091]

13. Zamani S, Sohrabi A, Hosseini SM, Rahnamaye-Farzami M, Ak bari A. Deregulation of miR-21 and miR-29a in cervical cancer related to HPV infection. Microrna. 2019;8(2):110-5. doi 10.2174/2211536607666181017124349. [PubMed: 30332981].

14. Parikh SA, Patel VA, Ratner D. Advances in the management of cutaneous squamous cell carcinoma. F100oPrime Rep. 2014;6:70. doi: 10.12703/P6-70. [PubMed: 25165569]. [PubMed Central: PMC4126542].

15. Pakzad R, Ghoncheh M, Pournamdar Z, Pakzad I, Momenimovahed Z, Salehiniya H, et al. Spatial analysis of skin cancer incidence in Iran. Asian Pac J Cancer Prev. 2016;17(S3):33-7. doi:10.7314/apjcp.2016.17.s3.33. [PubMed: 27165204].

16. Razi S, Rafiemanesh H, Ghoncheh M, Khani Y, Salehiniya H. Changing trends of types of skin cancer in Iran. Asian Pac J Cancer Prev. 2015;16(12):4955-8. doi: 10.7314/apjcp.2015.16.12.4955. [PubMed 26163621].

17. Razi S, Enayatrad M, Mohammadian-Hafshejani A, Salehiniya H, Fathali-Loy-Dizaji M, Soltani S. The epidemiology of skin cancer and its trend in Iran. Int J Prev Med. 2015;6:64. doi: 10.4103/2008-7802.161074. [PubMed: 26288708]. [PubMed Central: PMC4521305].

18. Nasser N, Nasser Filho N, Lehmkuhl RL. Squamous cell cancer-31year epidemiological study in a city of south Brazil. An Bras Dermatol. 2015;90(1):21-6. doi: 10.1590/abd1806-4841.20153465. [PubMed 25672295]. [PubMed Central: PMC4323694].

19. Gurudutt VV, Genden EM. Cutaneous squamous cell carcinoma of the head and neck. J Skin Cancer. 2011;2011:502723. doi:10.1155/2011/502723. [PubMed: 21461387]. [PubMed Central: PMC3064996].

20. Kabir S, Schmults CD, Ruiz ES. A review of cutaneous squamous cell carcinoma epidemiology, diagnosis, and management. Int Jo Cancer Manage. 2018;11(1). doi: 10.5812/ijcm.60846. 
Table 1. Frequency and Epidemiology of cSCC at Faghihi Hospital of Shiraz, in 2015 - 2016.

\begin{tabular}{|c|c|c|c|}
\hline Variables & 2015, No. (\%) & 2016, No. (\%) & Total, No. (\%) \\
\hline \multicolumn{4}{|l|}{ Sex } \\
\hline Female & $37(25.7)$ & $46(27.5)$ & $83(27)$ \\
\hline Male & $107(74.3)$ & $121(72.5)$ & $228(73)$ \\
\hline \multicolumn{4}{|l|}{ Burn } \\
\hline With out & $122(84.7)$ & $137(82)$ & $259(83)$ \\
\hline No result & $16(11.1)$ & $22(13.2)$ & $38(12.2)$ \\
\hline \multicolumn{4}{|l|}{ Ulcer } \\
\hline With & $8(5.5)$ & $37(22.1)$ & $45(14.5)$ \\
\hline With out & $136(94.5)$ & $130(77.9)$ & $266(85.5)$ \\
\hline With & $2(1.4)$ & $12(7.2)$ & $14(4.5)$ \\
\hline With out & $142(98.6)$ & $155(92.8)$ & $297(95.5)$ \\
\hline \multicolumn{4}{|c|}{ Immune suppression } \\
\hline With & $17(11.8)$ & $21(12.6)$ & $38(12.2)$ \\
\hline With out & $111(77)$ & $124(74.2)$ & $235(75.6)$ \\
\hline No result & $16(11.2)$ & $22(13.2)$ & $38(12.2)$ \\
\hline \multicolumn{4}{|l|}{ Metastases } \\
\hline With & $4(2.8)$ & $3(1.8)$ & $7(2.3)$ \\
\hline With out & $140(97.2)$ & $164(98.2)$ & $304(97.7)$ \\
\hline \multicolumn{4}{|c|}{ Pathological history } \\
\hline Early & $4(2.8)$ & $4(2.4)$ & $8(2.6)$ \\
\hline In situ & $7(4.9)$ & $13(7.8)$ & $20(6.4)$ \\
\hline Invasive & $2(1.4)$ & $1(0.6)$ & $3(1)$ \\
\hline MT & $1(0.7)$ & $42(25)$ & $43(13.8)$ \\
\hline MDC & $37(25.7)$ & $43(26)$ & $80(25.7)$ \\
\hline No SCC & $38(26.4)$ & $48(29)$ & $86(27.7)$ \\
\hline PDC & $9(6.2)$ & $7(4.2)$ & $16(5.1)$ \\
\hline WDC & $46(32)$ & $51(30.5)$ & $97(31.1)$ \\
\hline \multicolumn{4}{|l|}{ Thickness, mm } \\
\hline 1 & $6(4.2)$ & $1(0.6)$ & $7(2.2)$ \\
\hline 2 & $40(28)$ & $38(23)$ & $78(25)$ \\
\hline 3 & $56(39)$ & $44(26.3)$ & $100(32)$ \\
\hline 4 & $13(9)$ & $35(21)$ & $48(15.4)$ \\
\hline 5 & $11(7.6)$ & $22(13.2)$ & $33(10.6)$ \\
\hline 6 & $4(2.8)$ & $13(7.8)$ & $17(5.5)$ \\
\hline 7 & $4(2.8)$ & $3(1.8)$ & $7(2.2)$ \\
\hline 8 & $2(1.4)$ & $3(1.8)$ & $5(1.6)$ \\
\hline 9 & $4(2.8)$ & $0(0)$ & $4(1.3)$ \\
\hline 10 & $1(0.7)$ & $7(4.2)$ & $8(2.6)$ \\
\hline
\end{tabular}




\begin{tabular}{|c|c|c|c|c|}
\hline & $\geq 11$ & $3(2.1)$ & $1(0.6)$ & $7(1.2)$ \\
\hline \multicolumn{5}{|c|}{ Location } \\
\hline & Abdominal wall & $1(0.7)$ & $\mathrm{o}(0)$ & $1(0.3)$ \\
\hline & Back & $1(0.7)$ & $0(0)$ & $1(0.3)$ \\
\hline & Cheek & $11(7.6)$ & $10(6)$ & $21(6.6)$ \\
\hline & Chest & $1(0.7)$ & $2(1.2)$ & $3(1)$ \\
\hline & Chin & $1(0.7)$ & $1(0.6)$ & $2(0.6 \%)$ \\
\hline & Ear & $10(6.9)$ & $13(7.8)$ & $23(7.4)$ \\
\hline & Eyelid & $5(3.5)$ & $3(1.8)$ & $8(2.6)$ \\
\hline & Face & $19(13)$ & $12(7.2)$ & $31(10)$ \\
\hline & Finger & $0(0)$ & $1(0.6)$ & $1(0.3)$ \\
\hline & Foot & $6(4)$ & $8(4.8)$ & $14(4.5)$ \\
\hline & Forehead & $7(4.9)$ & $6(3.6)$ & $13(4.2)$ \\
\hline & Hand & $12(8.3)$ & $17(10)$ & $29(9.3)$ \\
\hline & Lower lip & $15(10.4)$ & $14(8.4)$ & $29(9.3)$ \\
\hline & Lymph node axillary & $1(0.7)$ & $0(0)$ & $1(0.3)$ \\
\hline & Nail bed & $0(0)$ & $1(0.6)$ & $1(0.3)$ \\
\hline & Neck & $2(1.4)$ & $2(1.2)$ & $4(1.3)$ \\
\hline & Nose & $29(20)$ & $29(17.4)$ & $58(18.6)$ \\
\hline & Scalp & $19(13)$ & $38(22.7)$ & $57(18.3)$ \\
\hline & Upper lip & $3(2)$ & $9(5.4)$ & $12(3.8)$ \\
\hline & Vagina & $1(0.7)$ & $1(0.6)$ & $2(0.6)$ \\
\hline Total & & $144(100)$ & $167(100)$ & $311(100)$ \\
\hline
\end{tabular}

Abbreviations: MDC, moderately differentiated squamous cell carcinoma; PDC, poorly differentiated carcinoma; WDC, well differentiated squamous cell carcinoma 